\title{
PREVALENCE OF MIDDLE MESIAL CANALS IN THE MESIAL ROOT OF FIRST PERMANENT MANDIBULAR MOLARS IN EGYPTIAN POPULATION: AN INVIVO COHORT RETROSPECTIVE CONE-BEAM COMPUTED TOMOGRAPHIC STUDY
}

\author{
Nehal Nabil Roshdy* and Sherif Adel El Khodary*
}

\begin{abstract}
Objective: The aim of the study was to detect the prevalence of middle mesial canals in the mesial root of first mandibular molars in Egyptian population by retrospective analysis of a large number of cone-beam computed tomography (CBCT) scans.

Materials and Methods: A total of 1090 CBCT scans of first permanent mandibular molars were obtained from patients who visited the Faculty of Dentistry, Cairo University, Egypt, for various purposes. CBCT scans were searched and only 800 subjects (374 males and 426 females) fulfilled the inclusion criteria.

Results: Middle mesial canal was present in $25.6 \%$ (205 of 800 ) of the subjects. The incidence of middle mesial canal bilaterally was $5.9 \%$ and unilaterally was $19.8 \%$. There was no statistically significant difference between males and females $(\mathrm{P}=0.079)$. Regarding the distribution of canal (Bilateral and unilateral); there was also no statistically significant difference between males and females $(P=0.056)$.

Conclusion: Among mandibular first molars, there is a high prevalence of a middle mesial canal in the Egyptian population. Detection of its presence is essential to achieve successful endodontic treatment.
\end{abstract}

KEY WORDS: Middle mesial canal- root canal- anatomy- first mandibular molar-CBCT

\section{INTRODUCTION}

Detailed knowledge of the internal teeth anatomy is crucial to achieve the objectives of endodontic therapy, which is to limit or alleviate apical periodontitis. The configuration variability as well as the canal number pose clinical challenge preventing the clinician from achieving this goal. Failure to identify and debride all the canals results in incomplete instrumentation and preservation of

* Lecturer in Endodontics, Faculty of Dentistry, Cairo University 
bacteria which compromise the root canal treatment outcome. ${ }^{(1)}$

The mesial root of permanent mandibular molars often shows complex anatomy. However, the most frequent anatomy is the presence of two canals in the mesial root, and one or two canals in the distal root.(1) Nevertheless, the variation incidence is relatively high including extra canals, separate distolingual and mesiobuccal roots, together with, an extra third canal in the mesial root. ${ }^{(2)}$. Pomeranz et $\mathrm{al}^{(3)}$, classified the middle mesial canal (MM) into 3 possible canal configurations: Fin; where the file passes freely between the main mesial canal (ML or $\mathrm{MB}$ ) and the MM canal (transverse anastomosis), confluent; where the MM canal unites with the main canals in the apical third and independent: where, the MM canal starts with a separate orifice and ends up with an independent apical foramen. Few clinical studies had investigated the prevalence of the middle mesial canal in mandibular molars

For the assessment of complicated root canal anatomies, conventional radiographic images don't seem beneficial though they are widely used in endodontic treatment. The usage of threedimensional (3D) imaging techniques such as; CBCT provides more details about the root canal morphology and shows more sensitivity for the detection of supplemental canals ${ }^{(4,5)}$. Studies have shown the accurate ability of CBCT scanning in the assessment of the root canal morphology, thereby granting the clinician accurate appraisal of the outcome of root canal treatments ${ }^{(6) .}$

Studies on the root canal anatomy of mandibular first molar have been performed on several populations ${ }^{(7)}$. However, a comprehensive search in literature showed insufficiency of the available studies performed on the root canal morphology of the Egyptian population. Hence, the purpose of the current study was to provide an investigation on the prevalence of middle mesial canal in the mandibular first molar in Egyptian population utilising cone beam computed tomography (CBCT)

\section{MATERIALS AND METHODS}

\section{Patient selection:}

The protocol was reviewed and approved by the institutional review board at the Faculty of Dentistry (Cairo University) in Egypt. CBCT scans of human first permanent mandibular molars were purchased from patients who visited the Faculty of Dentistry, Cairo University, Egypt, for various purposes between November 2015 and June 2017. CBCT scans were attained for dental examination, diagnosis, orthodontic treatment or implant surgery. Therefore, our study subjects were not exposed to unnecessary radiation. All the records were selected from Egyptian population. The patients' names were omitted by the radiographic centre (A third party), while the patients sex was recorded. CBCT scans of 1090 subjects were searched, only 800 subject (374 males and 426 females) fulfilled the following inclusion criteria:

1. Age between 15 and 60 years

2. Fully erupted first permanent mandibular molar bilaterally.

3. First permanent mandibular molar with fully matured-apices.

4. First permanent mandibular molar free of root canal fillings, posts and crown restorations.

\section{Radiographic Assessment:}

The CBCT images were seized with CBCT device (Scanora 3D, Soredex, Palodex group, Finland) with the following parameters: $85 \mathrm{kV}$, $15 \mathrm{~A}, 0.3 \mathrm{~mm}$ voxel size and the slice thickness were $1.0 \mathrm{~mm}$. All CBCT exposures were taken by a licensed radiologist, with the minimum exposure required for satisfactory image quality. Crosssectional images in the coronal, axial and sagittal sections were reconstructed by using OnDemand 3D software (Cybermed, Seoul, Korea). CBCT sections were thoroughly examined at a $1.0 \mathrm{~mm}$. 
The CBCT images were analysed in a dark room. To ensure optimum visualization, the brightness and the contrast of the images were accustomed using the software image processing tool. Intraexaminer calibration of the CBCT images was first performed, to check the accuracy of the assessment. All of the images were evaluated separately by two examiners twice, with a 2 -week time interval between the assessments. CBCT images were inspected simultaneously to reach a consensus for the interpretation of the radiographic findings.

\section{Statistical analysis:}

Data were presented as frequencies and percentages. Chi-square test was used to compare between males and females. The significance level was set at $\mathrm{P} \leq 0.05$. Statistical analysis was performed with IBM Corporation, NY, USA. SPSS, Inc., an IBM Company. Statistics Version 20 for Windows.

\section{RESULTS}

\section{Prevalence of MM canal}

Of the 800 patients, 205 subjects (25.6\%) showed middle mesial canal in the mandibular root of first permanent mandibular molars Figure(1). The existence of middle mesial canal bilaterally was $5.9 \%$ (47of 800) and unilaterally was $19.8 \%$ (158 of $800)$ of the subjects. The difference was statistically significant $(\mathrm{P}=0.056)$.

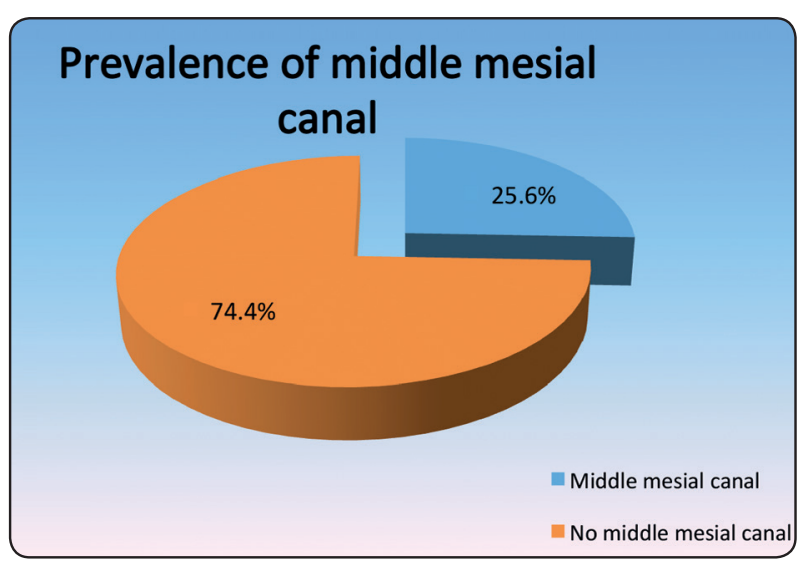

Fig. (1): Pie chart representing the prevalence of middle mesial canal in the Egyptian population

\section{Prevalence in males and females}

The overall prevalence of middle mesial canal in females was $28.2 \%$ (120 of 426) and $22.7 \%$ in males (85of374) with no statistically significant difference between males and females $(\mathrm{P}=0.079)$. (figure 2)

Regarding the distribution of canal (Bilateral and unilateral); there was also no statistically significant difference between males and females ( $P=0.056$ ). (Table 1)

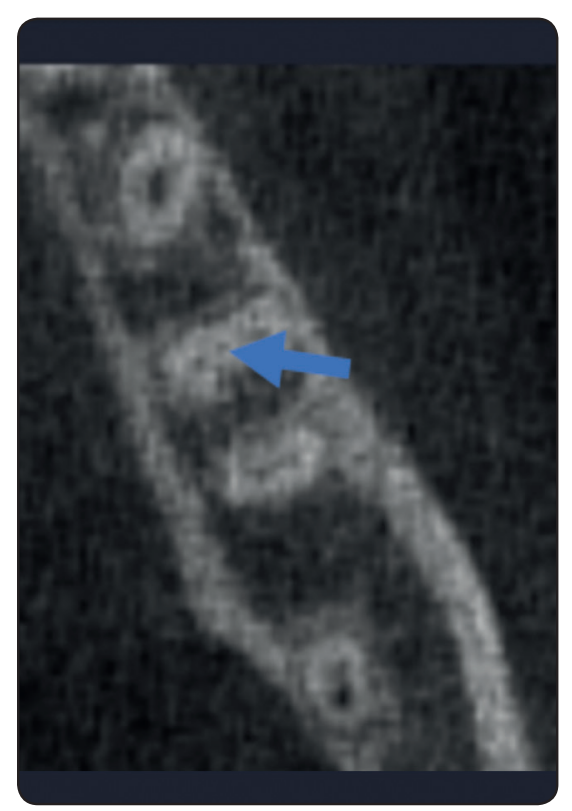

Fig. (2): CBCT scan showing Middle Mesial canal in mandibular first permanent molar (Left side) Blue arrow.

\section{DISCUSSION}

The most current origins of endodontic failure and flare-ups is the failure to recognize unusual canal configuration, identify extra canals and subsequent incomplete instrumentation. ${ }^{(8,9)}$. Usually, the classic literature articles describe the presence of two canals in the mesial root of mandibular molars ${ }^{(10,11)}$, although Vertucci and Williams ${ }^{(12)}$, as well as Barker et al ${ }^{(13)}$ were the first to provide evidence of the existence of a separate third mesial canal. This canal can be independent with a separate apical foramen or may fuse with either 
the mesiobuccal or the mesiolingual canal ${ }^{(14)}$. Relatively few studies have thoroughly evaluated the mesial root canal anatomy of mandibular first molars in ethnic populations by using CBCT images ${ }^{(7,15)}$. Thus, the aim of the current study was to determine the prevalence of middle mesial canal in the mandibular first permanent molars, in the Egyptian population by retrospectively analyzing great number of CBCT scans in vivo.

CBCT was used as it is a non-invasive in-vivo method, that allows utilizing large number of samples ${ }^{(7,15)}$ on top of, comparing the differences in gender and the bilateral prevalence of anatomic discripiancies ${ }^{(7,15,16)}$. The scans provide 3-dimensional images at a relatively low radiation dose with a small field of view, without anatomic superimposition or geometric distortion (17). Mirmohammadi et $\mathrm{al}^{(18)}$, indicated that the accuracy of CBCT imaging with a 6 FOV and 0.125 voxel size for detecting the second MB canal was $96 \%$. La et al ${ }^{(19)}$ suggested the importance of utilising CBCT imaging in the clinical detection and management of a separate middle mesial canal in mandibular first molar. The scans used in our study were previously taken for other diagnostic or therapeutic reasons. Thus, the concept of "as low as reasonably achievable" was followed ${ }^{(20)}$.

In the current study, only untreated, healthy, fully developed mandibular molar teeth were included to ensure the integrity of the original morphology of the root canals. Accuracy in detecting MM canals was ensured by excluding teeth with full-coverage restorations and root canal-treated teeth to avoid the image artifacts.

The present study showed that the prevalence of a third canal (middle mesial) in mandibular molars was $25.6 \%$ in the Egyptian population. Nosrat et $\mathrm{al}^{(21)}$, reported the prevalence rate of middle mesial canals as $20 \%$ of molars and that there was no statistically significant difference between males and females. Our study demonstrated that the overall prevelance of MM canal in females was $28.2 \%$ (120 of 426 ) compared to $22.7 \%$ in males (85 of 374) with no significant difference between them $(\mathrm{P}=0.079)$. Forner et al (22) reported the existence of middle mesial canal was up to $14.8 \%$ in accordance with Akbarzadeh et al ${ }^{(23)}$ who showed that the total prevalence of MM canal was $14.7 \%$. While, Tahmasbi ${ }^{(24)}$ found that $10.7 \%$ of their cases had MM canals originating from the cervical third. On the other hand, Azim et al ${ }^{(25)}$ recognized the existence of combined true MM canals and isthmi as $46 \%$ in mandibular molars upon working under magnification after troughing in the mesial root within a 2-mm depth. The variability in results can be attributed to several possible reasons such as ethnic population, sample size and study design ${ }^{(26)}$

\section{CONCLUSION}

Within the parameters of this retrospective invivo CBCT study, high prevalence of the MM canal in the first permanent mandibular molar of the Egyptian population was detected. Thereby, enhanced knowledge of the morphological variations can improve the rate of success for both non-surgical and surgical root canal treatment and consequently avoids failure of treatment. Invivo CBCT analysis remains as a non-invasive and clinically effective tool for determining root and canal morphology.

\section{ACKNOWLEDGMENT}

The authors deny any conflict of interest or financial affiliation related to this study.

\section{REFERENCES}

1. Vertucci, F.J. Root canal anatomy of the human permanent teeth. OOO1984; 58, 589-599.

2. Arora A, Acharya SR, Sharma P. Endodontic treatment of a mandibular first molar with 8 canals: A case report. Restor Dent Endod 2015;40:75-8.

3. Pomeranz HH, Eidelman DL, Goldberg MG. Treatment considerations of the middle mesial canal of mandibular first and second molars. J Endod 1981;7:565-8. 
4. de Toubes KM, Cortes MI, Valadares MA, et al. Comparative analysis of accessory mesial canal identification in mandibular first molars by using four different diagnostic methods. J Endod 2012;38:436-41.

5. Plotino G, Grande NM, Pecci R, et al. Three-dimensional imaging using microcomputed tomography for studying tooth macromorphology. J Am Dent Assoc 2006;137: 1555-61.

6. Zhang R, Wang H, Tian YY, et al. Use of cone-beam computed tomography to evaluate root and canal morphology of mandibular molars in Chinese individuals. Int Endod $\mathrm{J}$ 2011;44:990-9.

7. Huang C, Chang Y, Chuang M, et al. Evaluation of root and canal systems of mandibular first molars in Taiwanese individuals using cone-beam computed tomography. J Formos Med Assoc 2010;109:303-8.

8. Slowey RR. Root canal anatomy. Road map to successful endodontics. Dent Clin North Am 1979; 23:555-73.

9. Shahi S, Yavari HA, Rahimi S, Torkamani R. Root canal morphology of human mandibular first permanent molars in an Iranian population. JODDD 2008;2:20-3.

10. Skidmore AE, Bjorndal AM. Root canal morphology of the human mandibular first molar. Oral Surg Oral Med Oral Pathol 1971;32:778-84.

11. Hartwell G, Bellizzi R. Clinical investigation of in vivo endodontically treated mandibular and maxillary molars. J Endod 1982;8:555-7.

12. Vertucci FJ, Williams RG. Furcation canals in the human mandibular first molar. Oral Surg Oral Med Oral Pathol 1974;38:308-14.

13. Barker BC, Parsons KC, Mills PR, Williams GL. Anatomy of root canals: III - permanent mandibular molars. Aust Dent J 1974; 19:408-13

14. Goel NK, Gill KS, Taneja JR. Study of root canals configuration in mandibular first permanent molar. J Indian Soc Pedod Prev Dent 1991;8:12-4.

15. Wang Y,Zheng Q, Zhou X, et al. Evaluation of the root and canal morphology of mandibular first permanent molars in a western Chinese population by conebeam computed tomography. J Endod 2010;36:1786-9.

16. Chen G, Yao H, Tong C. Investigation of the root canal configuration of mandibular first molars in a Taiwan Chinese population. Int Endod J 2009;42:1044-9.
17. Paes da Silva Ramos Fernandes LM, Rice D, OrdinolaZapata R, et al. Detection of various anatomic patterns of root canals in mandibular incisors using digital periapical radiography, 3 cone-beam computed tomographic scanners, and microcomputed tomographic imaging. J Endod 2014;40:42-5

18. Mirmohammadi H, Mahdi L, Partovi P, et al. Accuracy of cone-beam computed tomography in the detection of a second mesiobuccal root canal in endodontically treated teeth: an ex vivo study. J Endod 2015;41:1678-81.

19. La SH, Jung DH, Kim EC, Min KS. Identification of independent middle mesial canal in mandibular first molar using cone-beam computed tomography imaging. J Endod 2010;237:1-4.

20. Joint Position Statement of the American Association of Endodontists and the American Academy of Oral and Maxillofacial Radiology. Use of cone-beam computed tomography in endodontics. Available at: www.aaomr.org/ resource/resmgr/Docs/ AAOMR-AAE_postition_paper_ CB.pdf. Accessed September 17, 2013.

21. Nosrat Ali, Deschenes J, Tordik A, Hicks M and Fouad Ashraf. Middle mesial canals in mandibular molars: Incidence and related factors. J Endod 2015;41:28-32.

22. Forner Navarro L, Luzi A, Garcia AA, Garcia AH. Third canal in the mesial root of permanent mandibular first molars: review of the literature and presentation of 3 clinical reports and 2 in vitro studies. Med Oral Patol Oral Cir Bucal 2007;12: E605-9.

23. Akbarzadeh N, Aminoshariae A, Khalighinejad N, Palomo J M, Ali S, Kulild J C, Sadeghi G, and Mickel A. The Association between the Anatomic Landmarks of the Pulp Chamber Floor and the Prevalence of Middle Mesial Canals in Mandibular First Molars: An In Vivo Analysis. JEn$\operatorname{dod} 2017 ; 43(11): 1797-1801$

24. Tahmasbi M., Jalali P.,Nair M.K., Barghan S., and Nair U.P. Prevalence of Middle Mesial Canals and Isthmi in the Mesial Root of Mandibular Molars: An In Vivo Conebeam Computed Tomographic Study. JEndod 2017:43(7): 1080-83

25. Azim AA, Deutsch AS, Solomon CS. Prevalence of middle mesial canals in mandibular molars after guided troughing under high magnification: an in vivo investigation. $\mathrm{J}$ Endod 2015;41:164-8.

26. Sert S, Bayirli GS. Evaluation of the root canal configurations of the mandibular and maxillary permanent teeth by gender in the Turkish population. J Endod 2004;30:391-8. 